\title{
Pre-treatment hemoglobin levels are an independent prognostic factor in patients with non-small cell lung cancer
}

\author{
YUE-HUA ZHANG ${ }^{1,2^{*}}$, YUQUAN LU ${ }^{3 *}$, HONG LU $^{1}$, MENG-WEI ZHANG ${ }^{1}$, \\ YUE-MIN ZHOU ${ }^{3,4}$, XIANG-LEI LI ${ }^{1}$, PIN LV $^{1}$ and XIAO-YAN ZHAO ${ }^{1}$ \\ ${ }^{1}$ Department of Oncology, Huaihe Hospital of Henan University; ${ }^{2}$ Department of Oncology, The First Affiliated \\ Hospital of Henan University; ${ }^{3}$ International Joint Research Laboratory for Cell Medical Engineering of Henan; \\ ${ }^{4}$ Center for Translational Medicine, Huaihe Hospital of Henan University, Kaifeng, Henan 475001, P.R. China
}

Received November 8, 2017; Accepted May 9, 2018

DOI: $10.3892 /$ mco.2018.1628

\begin{abstract}
To date, few studies have reported the prognostic value of pre-treatment hemoglobin levels in patients with non-small cell lung cancer (NSCLC). In the present study, 416 patients with NSCLC were retrospectively reviewed. Univariate Cox proportional hazards regression analysis demonstrated that patients with normal pre-treatment hemoglobin (NPHb) levels had a greater chance of surviving for longer period, than did patients with low pre-treatment hemoglobin (LPHb) levels (HR, 2.05; 95\% CI, 1.63-2.57; P<0.001). After adjustment for age, sex, tumor-node-metastasis stage, Karnofsky performance status, lung lobectomy, chemotherapy and radiotherapy, multivariate Cox proportional hazards regression analysis revealed that LPHb was an independent predictor for the poor prognosis of patients with NSCLC (HR, 1.86; 95\% CI, 1.47-2.36; P<0.001). Estimation of the cumulative survival revealed that the overall survival of $\mathrm{NPHb}$ patients was significantly higher than that for $\mathrm{LBHb}$ patients $(\mathrm{P}<0.05)$, independent of whether the patients had received lung lobectomy or chemotherapy treatments. In conclusion,
\end{abstract}

Correspondence to: Dr Yuquan Lu, International Joint Research Laboratory for Cell Medical Engineering of Henan, Huaihe Hospital of Henan University, 115 Ximen Street, Kaifeng, Henan 475001, P.R. China

E-mail: 1113923@gmail.com

Dr Hong Lu, Department of Oncology, Huaihe Hospital of Henan University, 115 Ximen Street, Kaifeng, Henan 475001, P.R. China

E-mail: hhyyluhong@126.com

${ }^{*}$ Contributed equally

Abbreviations: NSCLC, non-small cell lung cancer; TNM, tumor-node-metastasis; KPS, Karnofsky performance status; $\mathrm{NPHb}$, normal pre-treatment hemoglobin; LPHb, low pre-treatment hemoglobin; HR, hazard ratio; CI, confidence interval; OS, overall survival

Key words: pre-treatment hemoglobin, non-small cell lung cancer, overall survival, case fatality rate, prognosis low pre-treatment hemoglobin levels were demonstrated to be an independent biomarker for poor prognosis in patients with NSCLC.

\section{Introduction}

Lung cancer is a common cause of mortality for both men and women (1). Despite advances in treatment, the five-year overall survival (OS) rate is only $16.3 \%$ (2). In the majority of cases, $>80 \%$ of lung cancer diagnoses are of the non-small cell lung cancer (NSCLC) type (3). To date, the disease prognosis is mainly based on the tumor-node-metastasis (TNM) staging system, the histologic type and certain mutational genetic analyses $(3,4)$. Although these factors strongly affect the treatment choice and outcomes of patients with NSCLC, the majority of these factors cannot be determined without invasive procedures, and the required mutational genetics analysis procedures are costly and provide insufficient evidence for validation (5-7). Therefore, it is necessary and worthwhile to identify clinical biomarkers that could economically and conveniently predict the prognosis of patients with NSCLC.

Hemoglobin is a biochemical biomarker assessed during clinical examination. Several reports have indicated that low hemoglobin levels are associated with poor survival in patients with NSCLC (8-10); however, contradictory reports also exist $(11,12)$. Whether hemoglobin levels, especially low pre-treatment hemoglobin (LPHb) levels, are an independent predictor for poor prognosis in patients with NSCLC requires further study for clarification.

In Henan, China, there reside $\sim 1,000,000,000$ people; to the best of our knowledge there is no regional data regarding the prognostic value of pre-treatment hemoglobin levels in patients with NSCLC. The aim of the present study was to investigate the prognostic value of pre-treatment hemoglobin levels for the survival of patients with NSCLC.

\section{Patients and methods}

Patients. From May 2010 to June 2017, 736 patients with lung cancer were diagnosed at the Henan University Huaihe Hospital (Henan, China). The clinical data were retrospectively collected. After excluding 320 ineligible subjects, a 


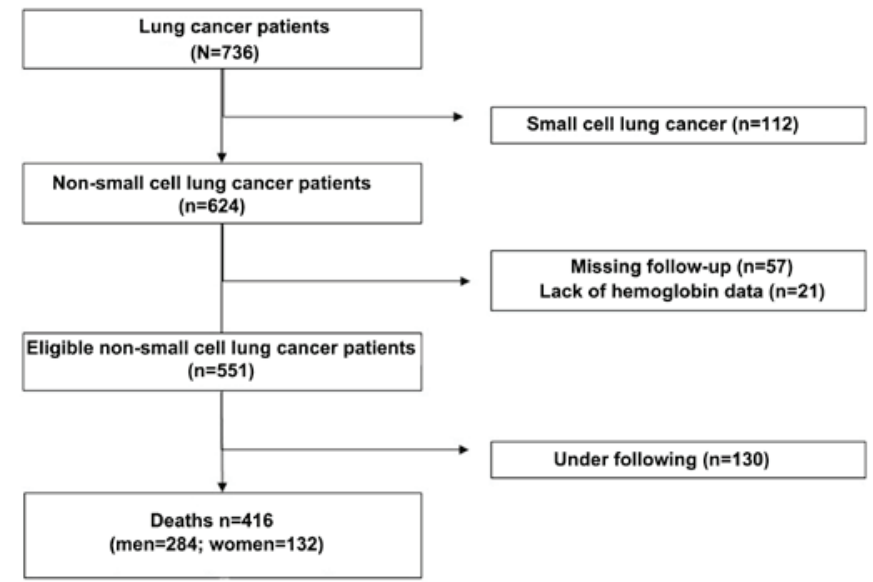

Figure 1. Schematic diagram of participant enrollment in the present study.

total of 416 patients with NSCLC (284 men and 132 women) were selected as subjects for the present study (Fig. 1). All cases of NSCLC were pathologically confirmed. The survival period for each subject was defined as the number of days from the date of diagnosis to the date of mortality. Patients were included in the present study if they had a verified diagnosis of NSCLC, regardless of whether they had received prior lung lobectomy, chemotherapy or radiotherapy treatments.

The clinical stage was assigned on the basis of the 8th Edition of the TNM Classification for Lung Cancer (13). Data regarding age, sex, histological cancer type, TNM stage, Karnofsky performance status (KPS) (14), lung lobectomy, chemotherapy, radiotherapy, smoking status, alcohol consumption, family history, diagnosis date, hemoglobin levels and date of mortality were obtained retrospectively from the patients' medical records, local death registration departments and telephone follow-ups. The study was approved by the Medical Ethics Committee of Henan University Huaihe Hospital.

Methods. The pre-treatment hemoglobin levels of the patients were obtained. The LPHb level was defined as $<120 \mathrm{~g} / \mathrm{l}$ of hemoglobin in men, and as $<110 \mathrm{~g} / 1$ in women. All patients were dichotomized into an LPHb group $(n=104)$ and a normal pre-treatment hemoglobin $(\mathrm{NPHb})$ group $(\mathrm{n}=312)$. Comparisons of clinical characteristics between the $\mathrm{LPHb}$ and $\mathrm{NPHb}$ groups were conducted using the Chi-squared $\left(\chi^{2}\right)$ test. For univariate Cox proportional hazards regression, age, sex, TNM stages, KPS scores, lung lobectomy status, chemotherapy, radiotherapy, smoking status, alcohol consumption, family history, and hemoglobin levels were dichotomized into a favorable group and an unfavorable group. Hazard ratios (HR) and 95\% confidence intervals (CI) were calculated to estimate associations between the observed factors and case fatality rate of patients with NSCLC. A subsequent multivariate analysis using Cox proportional hazards model estimated the prognostic influence of age, sex, TNM stage, KPS, lung lobectomy, chemotherapy, radiotherapy and hemoglobin levels on the case fatality rate of patients with NSCLC.

Survival curves were generated using the Kaplan-Meier analysis method, and the log-rank test was used to examine
Table I. Pre-treatment hemoglobin levels among clinicopathological and lifestyle factors in NSCLC patients.

\begin{tabular}{|c|c|c|c|}
\hline Factors & $\mathrm{NPHb}$ & $\mathrm{LPHb}$ & P-value \\
\hline Age (years) & & & $<0.001$ \\
\hline$\geq 65$ & 140 & 64 & \\
\hline$<65$ & 172 & 40 & \\
\hline Sex & & & 0.002 \\
\hline Male & 200 & 84 & \\
\hline Female & 112 & 20 & \\
\hline Histology & & & 0.004 \\
\hline Adenocarcinoma & 188 & 44 & \\
\hline $\mathrm{SqCC}$ & 91 & 48 & \\
\hline Other & 33 & 12 & \\
\hline TNM Stage & & & 0.089 \\
\hline I-III & 70 & 13 & \\
\hline IV & 150 & 56 & \\
\hline Others & 92 & 35 & \\
\hline KPS & & & 0.005 \\
\hline$<80$ & 131 & 60 & \\
\hline$\geq 80$ & 181 & 44 & \\
\hline Lung lobectomy & & & 0.006 \\
\hline Yes & 79 & 13 & \\
\hline No & 233 & 91 & \\
\hline Chemotherapy & & & 0.020 \\
\hline Yes & 148 & 63 & \\
\hline No & 164 & 41 & \\
\hline Radiotherapy & & & 0.066 \\
\hline Yes & 57 & 11 & \\
\hline No & 255 & 93 & \\
\hline Cigarette smoking & & & 0.002 \\
\hline Yes & 165 & 73 & \\
\hline No & 147 & 31 & \\
\hline Alcohol drinking & & & 0.112 \\
\hline Yes & 61 & 28 & \\
\hline No & 251 & 76 & \\
\hline Family history of cancer & & & 0.994 \\
\hline Yes & 18 & 6 & \\
\hline No & 294 & 98 & \\
\hline Survival year & & & $<0.001$ \\
\hline$<1$ year & 125 & 74 & \\
\hline$\geq 1$ year & 187 & 30 & \\
\hline
\end{tabular}

P-values were determined by Chi-squared $\left(\chi^{2}\right)$ test. NSCLC, non-small cell lung cancer; NPHb, normal pre-treatment hemoglobin (men, 120-160 g/l; women, 110-150 g/l); LPHb, low pre-treatment hemoglobin (men, $<120 \mathrm{~g} / \mathrm{l}$; women $\leq 110 \mathrm{~g} / \mathrm{l}$ ); SqCC, squamous cell carcinoma; TNM, tumor-node-metastasis; KPS, Karnofsky performance status.

differences in survival between the various hemoglobin groups. All statistical analyses were performed using the Stata software version 13 (Stata Corporation, College Station, TX, 
Table II. Univariate analysis of prognostic factors in patients with NSCLC.

\begin{tabular}{|c|c|c|c|c|c|}
\hline Factors & Favorable & Unfavorable & Hazard ratio (HR) & $95 \% \mathrm{CI}$ & P-value \\
\hline Age (years) & $<65$ & $\geq 65$ & 1.19 & $0.98-1.45$ & 0.078 \\
\hline Sex & Female & Male & 0.90 & $0.73-1.11$ & 0.313 \\
\hline TNM Stage & I-III & IV & 1.55 & $1.28-1.89$ & $<0.001$ \\
\hline KPS scores & $\geq 80$ & $<80$ & 1.50 & $1.24-1.83$ & $<0.001$ \\
\hline Lung lobectomy & Yes & No & 1.96 & $1.55-2.48$ & $<0.001$ \\
\hline Chemotherapy & Yes & No & 1.47 & $1.21-1.78$ & $<0.001$ \\
\hline Radiotherapy & Yes & No & 1.34 & $1.03-1.74$ & 0.030 \\
\hline Cigarette smoking & No & Yes & 1.07 & $0.88-1.30$ & 0.483 \\
\hline Alcohol consumption & No & Yes & 0.95 & $0.75-1.20$ & 0.660 \\
\hline Family history of cancer & No & Yes & 0.93 & $0.62-1.39$ & 0.720 \\
\hline Hemoglobin & $\mathrm{NPHb}$ & $\mathrm{LPHb}$ & 2.05 & $1.63-2.57$ & $<0.001$ \\
\hline
\end{tabular}

P-values were determined by univariate Cox proportional hazards regression analysis. NSCLC, non-small cell lung cancer; CI, confidence interval; TNM, tumor-node-metastasis; KPS, Karnofsky performance status; NPHb, normal pre-treatment hemoglobin (men, 120-160 g/l; women, 110-150 g/l); LPHb, low pre-treatment hemoglobin (men, $<120 \mathrm{~g} / \mathrm{l}$; women $\leq 110 \mathrm{~g} / \mathrm{l}$ ).

USA). $\mathrm{P}<0.05$ was considered statistically significant for all analyses.

\section{Results}

Patient characteristics. As presented in Table I, of the 416 patients, $178(42.8 \%)$ were non-smokers and $238(57.2 \%)$ were smokers. Histological diagnoses included 232 (55.8\%) adenocarcinomas, 139 (33.4\%) squamous cell carcinomas and $45(10.8 \%)$ other NSCLC types. In total, 83 (20.0\%) patients were at TNM stage I-III, 206 (49.5\%) at stage IV and 127 $(30.5 \%)$ patients had an unknown stage. Statistical analysis revealed that there were significant differences in hemoglobin levels between patients $\geq 65$ and $<65$ years of age $(\mathrm{P}<0.001)$, men and women $(\mathrm{P}=0.002)$, histological types $(\mathrm{P}=0.004), \mathrm{KPS}$ scores $(\mathrm{P}=0.005)$, treatment with or without lung lobectomy $(\mathrm{P}=0.006)$, treatment with or without chemotherapy $(\mathrm{P}=0.02)$, smokers and non-smokers $(\mathrm{P}=0.002)$, and survival time $(\mathrm{P}<0.001)$.

Univariate Cox proportional hazards regression analysis demonstrated that patients who were at TNM stage IV (HR, 1.55; 95\% CI, 1.28-1.89), had KPS scores <80 (HR, 1.50; 95\% CI, 1.24-1.83), did not receive lung lobectomy (HR, $1.96 ; 95 \%$ CI, 1.55-2.48), did not receive chemotherapy (HR, 1.47; 95\% CI; 1.21-1.78), did not receive radiotherapy (HR, 1.34; 95\% CI, 1.03-1.74), or had LPHb levels (HR, 2.05; $95 \%$ CI, 1.63-2.57) had a significantly increased case fatality rate (Table II). However, age, sex, smoking status, alcohol consumption and family history did not have any significant associations with the case fatality rate of patients with NSCLC (Table II).

Multivariate Cox proportional hazards regression analysis demonstrated that LPHb levels were independently associated with an increased case fatality rate (HR, 1.86; 95\% CI, 1.47-2.36; Table III). In addition, not receiving lung lobectomy (HR, 1.46; 95\% CI, 1.10-1.93), not receiving chemotherapy (HR, 1.34; 95\% CI, 1.07-1.67) and TNM stage IV were also independent and unfavorable prognostic factors (Table III).
Kaplan-Meier survival curve estimations revealed that patients with LPHb had a poorer OS than did patients with NPHb levels (log-rank test, $\chi^{2}=39.50 ; \mathrm{P}<0.001$; Fig, 2A). When the patients were subdivided by sex, the male LPHb patients had a poorer OS than the male NPHb patients (log-rank test, $\chi^{2}=38.38 ; \mathrm{P}<0.001$; Fig. $2 \mathrm{~B}$ ), a difference not observed between the counterpart female groups (log-rank test, $\chi^{2}=3.16 ; \mathrm{P}=0.076$; Fig. 2B). When the patients were subdivided according to lung lobectomy, the LPHb group had a poorer OS than the $\mathrm{NPHb}$ group in both the no lung lobectomy group (log-rank test, $\chi^{2}=27.35 ; \mathrm{P}<0.001$; Fig. $2 \mathrm{C}$ ) and the lung lobectomy group (log-rank test, $\chi^{2}=4.87 ; \mathrm{P}=0.027$; Fig. $2 \mathrm{C}$ ). The subdivision of patients according to chemotherapy treatment also demonstrated that the LPHb group had a poorer OS than the $\mathrm{NPHb}$ group, in both the no chemotherapy group (log-rank test, $\chi^{2}=21.36 ; \mathrm{P}<0.001$; Fig. 2D) and the chemotherapy group (log-rank test, $\chi^{2}=12.30 ; \mathrm{P}<0.001$; Fig. 2D).

\section{Discussion}

The present data suggested that pre-treatment hemoglobin levels, measured at the time of diagnosis, may be an independent predictor for the prognosis of patients with NSCLC. These data are concordant with those of previous studies (8-10); to the best of our knowledge, this is the first report of associations between pre-treatment hemoglobin levels and the prognosis of patients with NSCLC, independent of whether they had received chemotherapy and/or lobectomy, in Henan, China. Compared with previous studies $(8-11,15)$, the multivariate models performed in the current study included more factors, rendering the present results less confounded.

Low hemoglobin is common in oncological diseases, including in lung $(16,17)$, breast (17), gastric (18) and ovarian cancer (19). There is evidence for a correlation between hemoglobin levels and the prognosis of patients with NSCLC. The precise underlying mechanisms are not fully understood. Tumor cells secrete a number of soluble molecules, including 
Table III. Multivariate analysis of prognostic factors in patients with NSCLC.

\begin{tabular}{|c|c|c|c|c|c|}
\hline Factors & Favorable & Unfavorable & Hazard ratio (HR) & $95 \%$ CI & P-value \\
\hline Age (years) & $<65$ & $\geq 65$ & 1.01 & $0.82-1.25$ & 0.892 \\
\hline Sex & Female & Male & 0.90 & $0.72-1.12$ & 0.356 \\
\hline TNM Stage & I-III & IV & 1.31 & $1.04-1.65$ & 0.022 \\
\hline KPS scores & $<80$ & $\geq 80$ & 1.13 & $0.92-1.41$ & 0.247 \\
\hline Lung lobectomy & Yes & No & 1.46 & $1.10-1.93$ & 0.008 \\
\hline Chemotherapy & Yes & No & 1.34 & $1.07-1.67$ & 0.011 \\
\hline Radiotherapy & Yes & No & 1.09 & $0.82-1.45$ & 0.558 \\
\hline Hemoglobin & $\mathrm{NPHb}$ & $\mathrm{LPHb}$ & 1.86 & $1.47-2.36$ & $<0.001$ \\
\hline
\end{tabular}

P-values were determined by multivariate Cox proportional hazards regression analysis. NSCLC, non-small cell lung cancer; CI, confidence interval; TNM, tumor-node-metastasis; KPS, Karnofsky performance status; NPHb, normal pre-treatment hemoglobin (men, 120-160 g/l; women, 110-150 g/l); LPHb, low pre-treatment hemoglobin (men, $<120 \mathrm{~g} / \mathrm{l}$; women $\leq 110 \mathrm{~g} / \mathrm{l}$ ).
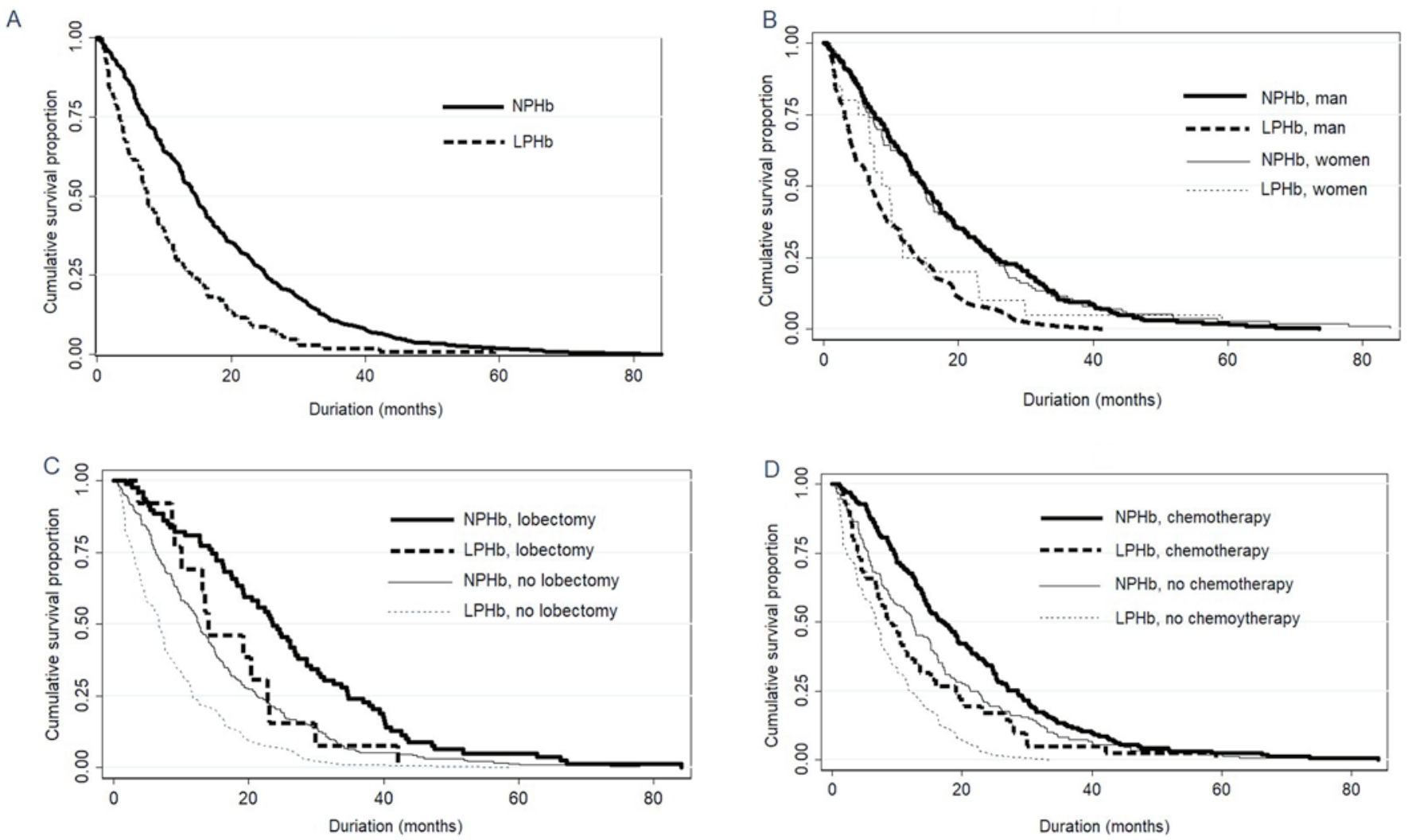

Figure 2. Cumulative survival proportion of patients with NSCLC according to their pre-treatment hemoglobin levels. (A) Overall survival of NPHb and LPHb patients with NSCLC (log-rank test, $\chi^{2}=39.50 ; \mathrm{P}<0.001$ ). (B) LPHb patients had a poorer overall survival than NPHb patients among men (log-rank test, $\chi^{2}=38.38 ; \mathrm{P}<0.001$ ), but not among women (log-rank test, $\chi^{2}=3.16 ; \mathrm{P}=0.076$ ). (C) LPHb patients had a poorer overall survival than NPHb patients in the no lung lobectomy group (log-rank test, $\chi^{2}=27.35 ; \mathrm{P}<0.001$ ) and the lung lobectomy group (log-rank test, $\chi^{2}=4.87 ; \mathrm{P}=0.027$ ). (D) LPHb group had a poorer overall survival than NPHb patients in the no chemotherapy group (log-rank test, $\left.\chi^{2}=21.36 ; \mathrm{P}<0.001\right)$ and the chemotherapy group $\left(\log\right.$-rank test, $\left.\chi^{2}=12.30 ; \mathrm{P}<0.001\right)$. NSCLC, non-small cell lung cancer; NPHb, normal pre-treatment hemoglobin (men, 120-160 g/l; women, 110-150 g/l); LPHb, low pre-treatment hemoglobin (men, $<120 \mathrm{~g} / 1$; women $\leq 110 \mathrm{~g} / \mathrm{l})$.

interleukin-6 (IL-6) and tumor necrosis factor- $\alpha$ (TNF- $\alpha$ ). These molecules could decrease hemoglobin by changing the hematopoietic environment $(20,21)$, suppressing erythropoiesis and erythropoietin (EPO) (22), and impairing the EPO response in erythroid progenitor cells (23). Furthermore, in patients with bone metastasis, bone marrow involvement may lead to bone morrow failure, which may then cause low hemoglobin levels (24) and subsequently lead to hypoxia, which could induce genomic changes and enhance the development of malignancy (25). Hypoxia may also boost tumor angiogenesis and accelerate metastasis (26). In addition, hypoxia may enhance tumor cell resistance to chemotherapy and radiotherapy through the development of multi-drug resistance (27). 
A major strength of the present study was the inclusion of a large number of patients with NSCLC, all with a complete set of clinical data, including the pre-treatment hemoglobin levels, the complete survival period, records of multiple treatments, the family history and lifestyle details, including smoking status and alcohol consumption; this enabled us to investigate the prognostic value of pre-treatment hemoglobin levels with decreased sample bias and offset heterogeneity. However, there are also limitations to the present study. First, it was retrospective, and the information on post-treatment recurrence was insufficient. Second, these data did not observe interaction of post-treatment hemoglobin levels with survival rate.

Both lung lobectomy and chemotherapy treatments were associated with the prognosis of patients with NSCLC. However, neither significantly affected the prognostic value of the pre-treatment hemoglobin levels in the present study. The TNM stage was also independently associated with the NSCLC prognosis, which is in line with previous studies $(28,29)$.

In conclusion, the present study suggests that low pre-treatment hemoglobin levels could be an independent biomarker for poor prognosis in patients with NSCLC. In future clinical studies, hemoglobin levels should be considered during the work-up of patients with NSCLC in prospective trials, in order to confirm its prognostic significance.

\section{Acknowledgements}

Not applicable.

\section{Funding}

No funding was received.

\section{Availability of data and materials}

The datasets used and/or analyzed during the current study are available from the corresponding author on reasonable request.

\section{Authors' contirbutions}

YHZ made substantial contributions to data collection and was a major contributor in writing the manuscript. YQL analyzed and interpretated the data, contributed to manuscript preparation and revision and gave final approval for the version to be published. HL was responsible for the acquisition of data and the Institutional Review Board application, conducted data interpretation, and gave final approval for the version to be published. MWZ and YMZ agreed to be accountable for all aspects of the work in ensuring that questions related to the accuracy or integrity of any part of the work are appropriately investigated and resolved. XLL made substantial contributions to conception and design of the present study. PL and XYZ made substantial contributions to the design of the present study and acquisition of data. All authors read and approved the final manuscript.

\section{Ethics approval and consent to participate}

The study was approved by the Medical Ethics Committee of Henan University Huaihe Hospital.

\section{Consent for publication}

Not applicable.

\section{Competing interests}

The authors declare that they have no compteing interests.

\section{References}

1. Siegel RL, Miller KD and Jemal A: Cancer Statistics, 2017. CA Cancer J Clin 67: 7-30, 2017.

2. Alberg AJ, Brock MV, Ford JG, Samet JM and Spivack SD: Epidemiology of lung cancer: Diagnosis and management of lung cancer, 3rd ed: American college of chest physicians evidence-based clinical practice guidelines. Chest 143 (5 Suppl): e1S-e29S, 2013.

3. Ettinger DS, Wood DE, Aisner DL, Akerley W, Bauman J, Chirieac LR, D'Amico TA, DeCamp MM, Dilling TJ, Dobelbower M, et al: Non-small cell lung cancer, version 5.2017, NCCN clinical practice guidelines in oncology. J Natl Compr Canc Netw 15: 504-535, 2017.

4. Clark GM: Prognostic factors versus predictive factors: Examples from a clinical trial of erlotinib. Mol Oncol 1: 406-412, 2008.

5. Brown T, Pilkington G, Bagust A, Boland A, Oyee J, Tudur-Smith C, Blundell M, Lai M, Martin Saborido C, Greenhalgh J, et al: Clinical effectiveness and cost-effectiveness of first-line chemotherapy for adult patients with locally advanced or metastatic non-small cell lung cancer: A systematic review and economic evaluation. Health Technol Assess 17: 1-278, 2013.

6. Greenhalgh J, Dwan K, Boland A, Bates V, Vecchio F, Dundar Y, Jain P and Green JA: First-line treatment of advanced epidermal growth factor receptor (EGFR) mutation positive non-squamous non-small cell lung cancer. Cochrane Database Syst Rev: CD010383, 2016.

7. Palma JF, Das P and Liesenfeld O: Lung cancer screening: Utility of molecular applications in conjunction with low-dose computed tomography guidelines. Expert Rev Mol Diagn 16: 435-447, 2016

8. Tomita M, Shimizu T, Hara M, Ayabe T and Onitsuka T: Impact of preoperative hemoglobin level on survival of non-small cell lung cancer patients. Anticancer Res 28: 1947-1950, 2008.

9. Gauthier I, Ding K, Winton T, Shepherd FA, Livingston R, Johnson DH, Rigas JR, Whitehead M, Graham B and Seymour L: Impact of hemoglobin levels on outcomes of adjuvant chemotherapy in resected non-small cell lung cancer: The JBR.10 trial experience. Lung Cancer 55: 357-363, 2007.

10. Aoe K, Hiraki A, Maeda T, Katayama H, Fujiwara K, Tabata M, Kiura K, Ueoka $\mathrm{H}$ and Tanimoto M: Serum hemoglobin level determined at the first presentation is a poor prognostic indicator in patients with lung cancer. Intern Med 44: 800-804, 2005.

11. Trufelli DC, Moraes TV, Lima AA and Giglio AD: Epidemiological profile and prognostic factors in patients with lung cancer. Rev Assoc Med Bras (1992) 62: 428-433, 2016.

12. Watine J: Blood hemoglobin as an independent prognostic factor in surgically resected stages I and II non-small cell lung cancer patients. Ann Thorac Surg 73: 2034-2035; Author reply 2035, 2002.

13. Kay FU, Kandathil A, Batra K, Saboo SS, Abbara S and Rajiah P: Revisions to the tumor, node, metastasis staging of lung cancer (8th edition): Rationale, radiologic findings and clinical implications. World J Radiol 9: 269-279, 2017.

14. Schag CC, Heinrich RL and Ganz PA: Karnofsky performance status revisited: Reliability, validity, and guidelines. J Clin Oncol 2: 187-193, 1984

15. Langendijk H, de Jong J, Wanders R, Lambin P and Slotman B: The importance of pre-treatment haemoglobin level in inoperable non-small cell lung carcinoma treated with radical radiotherapy. Radiother Oncol 67: 321-325, 2003.

16. Holgersson G, Sandelin M, Hoye E, Bergström S, Henriksson R, Ekman S, Nyman J, Helsing M, Friesland S, Holgersson M, et al: Swedish lung cancer radiation study group: The prognostic value of anaemia, thrombocytosis and leukocytosis at time of diagnosis in patients with non-small cell lung cancer. Med Oncol 29: 3176-3182, 2012. 
17. Ray-Coquard I, Morère JF, Scotté F, Cals L and Antoine EC: Management of anemia in advanced breast and lung cancer patients in daily practice: Results of a French survey. Adv Ther 29: 124-133, 2012.

18. Vannella L, Lahner E, Osborn J and Annibale B: Systematic review: Gastric cancer incidence in pernicious anaemia. Aliment Pharmacol Ther 37: 375-382, 2013.

19. Altman AD, Liu XQ, Nelson G, Chu P, Nation J and Ghatage P: The effects of anemia and blood transfusion on patients with stage III-IV ovarian cancer. Int J Gynecol Cancer 23: 1569-1576, 2013.

20. Banzet S, Sanchez H, Chapot R, Bigard X, Vaulont $S$ and Koulmann N: Interleukin-6 contributes to hepcidin mRNA increase in response to exercise. Cytokine 58: 158-161, 2012.

21. Sun CC, Vaja V, Babitt JL and Lin HY: Targeting the hepcidin-ferroportin axis to develop new treatment strategies for anemia of chronic disease and anemia of inflammation. Am J Hematol 87: 392-400, 2012.

22. Wu Y, Antony S, Meitzler JL and Doroshow JH: Molecular mechanisms underlying chronic inflammation-associated cancers. Cancer Lett 345: 164-173, 2014.

23. Aapro M, Jelkmann W, Constantinescu SN and Leyland-Jones B: Effects of erythropoietin receptors and erythropoiesis-stimulating agents on disease progression in cancer. Br J Cancer 106: 1249-1258, 2012.

24. Tefferi A, Hudgens S, Mesa R, Gale RP, Verstovsek S, Passamonti F, Cervantes F, Rivera C, Tencer T and Khan ZM: Use of the functional assessment of cancer therapy-anemia in persons with myeloproliferative neoplasm-associated myelofibrosis and anemia. Clin Ther 36: 560-566, 2014
25. Schwab LP, Peacock DL, Majumdar D, Ingels JF, Jensen LC, Smith KD, Cushing RC and Seagroves TN: Hypoxia-inducible factor $1 \alpha$ promotes primary tumor growth and tumor-initiating cell activity in breast cancer. Breast Cancer Res 14: R6, 2012.

26. Li S, Meng W, Guan Z, Guo Y and Han X: The hypoxia-related signaling pathways of vasculogenic mimicry in tumor treatment. Biomed Pharmacother 80: 127-135, 2016.

27. Milane L, Duan Z and Amiji M: Role of hypoxia and glycolysis in the development of multi-drug resistance in human tumor cells and the establishment of an orthotopic multi-drug resistant tumor model in nude mice using hypoxic pre-conditioning. Cancer Cell Int 11: 3, 2011.

28. Ost D, Goldberg J, Rolnitzky L and Rom WN: Survival after surgery in stage IA and IB non-small cell lung cancer. Am J Respir Crit Care Med 177: 516-523, 2008

29. Tanaka F, Yanagihara K, Otake Y, Miyahara R, Kawano Y, Nakagawa T, Shoji T and Wada H: Surgery for non-small cell lung cancer: Postoperative survival based on the revised tumor-node-metastasis classification and its time trend. Eur J Cardiothorac Surg 18: 147-155, 2000. 